\title{
An Advanced Control System for Fine Coal Flotation
}

\author{
Quarterly Report \\ January 1 - March 31, 1998
}

\author{
By \\ G. T. Adel \\ G. H. Luttrell
}

Work Performed Under Contract No.: DE-AC22-95PC95150

\author{
For \\ U.S. Department of Energy \\ Office of Fossil Energy \\ Federal Energy Technology Center \\ P.O. Box 880 \\ Morgantown, West Virginia 26507-0880 \\ By \\ Department of Mining and Minerals Engineering \\ Virginia Polytechnic Institute and State University \\ Blacksburg, Virginia 24061
}




\section{Disclaimer}

This report was prepared as an account of work sponsored by an agency of the United States Government. Neither the United States Government nor any agency thereof, nor any of their employees, makes any warranty, express or implied, or assumes any legal liability or responsibility for the accuracy, completeness, or usefulness of any information, apparatus, product, or process disclosed, or represents that its use would not infringe privately owned rights. Reference herein to any specific commercial product, process, or service by trade

name, trademark, manufacturer, or otherwise does not necessarily constitute or imply its endorsement, recommendation, or favoring by the United States Government or any agency thereof. The views and opinions of authors expressed herein do not necessarily state or reflect those of the United States Government or any agency thereof. 
Technical Progress Report

Eighth Quarter

(January 1, 1998 - March 31, 1998)

\title{
AN ADVANCED CONTROL SYSTEM FOR FINE COAL FLOTATION
}

\author{
Principal Investigators \\ G.T. Adel and G. H. Luttrell \\ Department of Mining and Minerals Engineering \\ Virginia Polytechnic Institute and State University \\ Blacksburg, Virginia 24061
}

Contract Number

DE-AC22-95PC95150--08

\author{
DOE Project Officer \\ Carl Maronde \\ United States Department of Energy \\ Federal Energy Technology Center \\ P. O. Box 10940 \\ Pittsburgh, Pennsylvania 15236-0940
}

April 20, 1998

Revised: June 1, 1998

"US/DOE patent clearance is not required prior to the publication of this document." 


\begin{abstract}
A model-based flotation control scheme is being implemented to achieve optimal performance in the handling and treatment of fine coal. The control scheme monitors flotation performance through on-line analysis of ash content. Then, based on the economic and metallurgical performance of the circuit, variables such as collector dosage, frother dosage, and pulp level are adjusted using model-based control algorithms to compensate for feed variations and other process disturbances. Recent developments in sensor technology are being applied for on-line determination of slurry ash content.

During the eighth quarter of this project, the analysis of data collected during Task 2 (Sampling and Data Analysis) was completed, and significant progress was made on Task 3 (Model Building and Computer Simulation). Previously, a plant sampling campaign had been conducted at Pittston's Moss No. 3 preparation plant to provide data for the development of a mathematical process model and a model-based control system. During this campaign, a onehalf factorial design experiment, blocked into low and high feed rates, was conducted to investigate the effects of collector, frother, and pulp level on model parameters. In addition, samples were collected during the transient period following each change in the manipulated variables to provide data for confirmation of the dynamic process simulator. A residence time distribution (RTD) test was also conducted to estimate the mean residence time. This is a critical piece of information since no feed flowrate measurement is available, and the mean residence time can be used to estimate the feed flowrate. Feed samples were taken at timed intervals and floated in a laboratory flotation cell to investigate the magnitude of feed property disturbances and their duration. Finally, a model was constructed from population balance considerations to
\end{abstract}


describe the steady-state and dynamic behavior of the flotation circuit. The model was parameterized using data from the plant sampling campaign.

At present, a flotation circuit simulator has been designed and coding has begun. A model-based control strategy has also been conceived which is expected to allow manipulated variables to be adjusted quickly in response to disturbances to achieve target incremental ash values (and/or to maximize flotation circuit profitability). 


\section{TABLE OF CONTENTS}

ABSTRACT

page

TABLE OF CONTENTS

iv

LIST OF ILLUSTRATIONS, TABLES AND FIGURES

$\mathrm{V}$

EXECUTIVE SUMMARY

vi

INTRODUCTION

TECHNICAL DISCUSSION

2

Task 1 - Project Planning 2

Task 2 - Sampling and Data Analysis 2

Subtask 2.1 - Plant Sampling 2

Subtask 2.2 - Data Analysis $\quad 5$

Mass Balance $\quad 6$

$\begin{array}{lr}\text { Transient Behavior } & 9\end{array}$

Task 3 - Model Building and Computer Simulation 10

Subtask 3.1 - Model Building 10

Model Format $\quad 10$

Model Simplification $\quad 13$

Entrainment 14

Flotation Rate Parameter Estimates $\quad 16$

Residence Time Distribution $\quad 18$

Floatability Disturbances $\quad 19$

Subtask 3.2 - Simulator Development $\quad 20$

Subtask 3.3 - Control Strategy Evaluation 20

Subtask 3.4 - Expert System Development 21

Task 4 - Sensor Testing $\quad 21$

Subtask 4.1 - Calibration Testing $\quad 21$

Subtask 4.2 - Design and Fabrication $\quad 22$

Task 5 - Sample Analysis and Characterization 22

Task 6 - Equipment Procurement and Installation 22

Task 7 - Operation and Testing $\quad 22$

Task 8 - System Evaluation $\quad 22$

Task 9 - Decommissioning 22

Task 10 - Final Report 22

SUMMARY STATUS AND FUTURE WORK 23

$\begin{array}{ll}\text { NOMENCLATURE } & 25\end{array}$ 


\section{LIST OF ILLUSTRATIONS, TABLES AND FIGURES}

Figure 1. Schematic diagram of Pittston's Moss No. 3 flotation circuit (test F3 values shown).

page

Figure 2. Transient and steady-state samples collected during each test.

Figure 3. Flotation cell showing the variables used for the mass balance.

.

Figure 4. Transient response of $\%$ ash to manipulated variable changes.

6

Figure 5. Schematic of the four possible states of particles in a flotation cell. 11

Figure 6. Particle composition distribution for the feed sample from factorial test $2 . \quad 14$

$\begin{array}{ll}\text { Figure 7. Clean coal } 200 \times 400 \text { mesh. } & 15\end{array}$

$\begin{array}{ll}\text { Figure 8. Clean coal }-400 \text { mesh. } & 15\end{array}$

Figure 9. Ash $200 \times 400$ mesh. 16

$\begin{array}{ll}\text { Figure 10. Ash }-400 \text { mesh. } & 16\end{array}$

$\begin{array}{ll}\text { Figure 11. Clean coal high feed rate. } & 17\end{array}$

$\begin{array}{ll}\text { Figure 12. Clean coal low feed rate. } & 17\end{array}$

$\begin{array}{lr}\text { Figure 13. Ash at high feed rate. } & 18\end{array}$

$\begin{array}{ll}\text { Figure 14. Ash at low feed rate. } & 18\end{array}$

Figure 15. The experimental and fitted residence time distributions. 19

$\begin{array}{ll}\text { Figure 16. Floatability disturbances. } & 20\end{array}$

Table 1. Factorial Design Test Summary $\quad 4$ 


\section{EXECUTIVE SUMMARY}

Over the past thirty years, process control has spread from the chemical industry into the fields of mineral and coal processing. Today, process control computers, combined with improved instrumentation, are capable of effective control in many modern flotation circuits. Unfortunately, the classical methods used in most control strategies have severe limitations when used in froth flotation. For example, the nonlinear nature of the flotation process can cause single-input, single-output lines to battle each other in attempts to achieve a given objective. Other problems experienced in classical control schemes include noisy signals from sensors and the inability to measure certain process variables. Factors related to ore type or water chemistry, such as liberation, froth stability, and floatability, are often difficult or impossible to measure by conventional means.

The purpose of this project is to demonstrate an advanced control system for fine coal flotation. The demonstration is being carried out at an existing coal preparation plant by a team consisting of Virginia Polytechnic Institute and State University (VPI\&SU) as the prime contractor and J.A. Herbst and Associates as a subcontractor. The objectives of this work are: 1) to identify through sampling, analysis, and simulation those variables which can be manipulated to maintain grades, recoveries, and throughput rates at levels set by management; 2) to develop and implement a model-based computer control strategy that continuously adjusts those variables to maximize revenue subject to various metallurgical, economic, and environmental constraints; and 3) to employ a video-based optical analyzer for on-line analysis of ash content in fine coal slurries.

During the past two quarters, the steady-state and dynamic performance of the flotation bank at the test site (Pittston's Moss No. 3 plant), were characterized as part of Task 2 - 
Sampling and Data Analysis. Many of the findings from this sampling campaign were reported last quarter. Additional findings during the past quarter seem to support the conclusion that the plant is operating quite well. For example, a size and composition analysis of the plant flotation data indicates that nearly all clean coal recovery is due to particle attachment to air bubbles. Non-selective entrainment is only significant for -400 mesh mineral particles. An analysis of the flotation rate constants determined from plant data indicates that there is some opportunity for a control system to improve the flotation of the $200 \times 400$ mesh clean coal; however, changes in operating parameters seem to have little effect on the +200 and -400 mesh material. An analysis of the transient response obtained after a change in operating parameters indicates that there is an initial inverse response in clean coal ash content before a new steady-state is reached. Fortunately, such an inverse response provides an excellent rigorous test for validating a dynamic model. Disturbances in the system due to changes in flow rate seem to correlate well with changes in the overall plant flow rate. This is a convenient finding since there is no good way to incorporate a flow sensor in the feed line to the flotation bank. Finally, residence time distribution tests indicate that the four-cell flotation bank behaves like four perfect mixers in series with a mean retention time of four minutes. This is a convenient finding for modeling purposes.

At this time, a model structure has been identified and several simplifying assumptions have been made to allow the model to operate in an on-line configuration. Simulator development and control strategy evaluation are now underway, and sensor testing has resumed following the installation of a non-plugging sample line. At present, the project is roughly three months behind, but it is expected that some of this lost time can be recovered once the in-plant installation of the control system begins in June. 


\section{INTRODUCTION}

Over the past thirty years, process control has spread from the chemical industry into the fields of mineral and coal processing. Today, process control computers, combined with improved instrumentation for monitoring process parameters and performance, have demonstrated improved control in many modern flotation plants. Unfortunately, the classical methods used in most control strategies have severe limitations when it comes to control of froth flotation. The nonlinear nature of the flotation process, for example, can cause single-input, single-output control lines to battle each other in attempts to achieve a specific control objective. Other problems experienced in classical control schemes include noisy signals from measuring devices and the inability to measure certain process variables. Furthermore, factors related to ore type or process water chemistry, such as liberation characteristics, froth stability, and floatability, cannot be measured by conventional means.

The purpose of this project is to demonstrate an advanced control system for fine coal flotation at an operating coal preparation plant. The objectives of this work are: 1) to identify through sampling, analysis, and simulation those variables which can be manipulated in the plant to maintain grades, recoveries, and throughput rates at levels set by management; 2) to develop and implement a model-based computer control strategy that continuously adjusts those variables to maximize revenue subject to various metallurgical, economic, and environmental constraints; and 3) to employ a video-based optical analyzer for on-line analysis of ash content in fine coal slurries. The following is a summary of work completed during the eighth quarter of this project. 


\section{TECHNICAL DISCUSSION}

\section{Task 1 - Project Planning}

Project planning during the past quarter focused primarily on overseeing the analysis of the data collected under Task 2 (Sampling and Data Analysis), monitoring the efforts of the subcontractor (J.A. Herbst and Associates) in performing Task 3 (Model Building and Computer Simulation), and directing the continued work on the video-based ash analyzer (Task 4).

\section{Task 2 - Sampling and Data Analysis}

Subtask 2.1 - Plant Sampling: During the latter part of November, 1997, a plant sampling campaign was conducted at the Moss No. 3 preparation plant owned and operated by Pittston Coal Company. The purpose of this sampling campaign was to characterize the dynamic and steady-state performance of the flotation bank in preparation for modeling and process control activities. This bank currently treats approximately 100 tph of -100 mesh coal to produce both steam and metallurgical grade products.

A schematic diagram of the flotation bank at the Moss No. 3 plant is shown in Figure 1. As shown, the bank consists of four 1000-cubic-foot Wemco cells operating at a feed flow rate of approximately $8000 \mathrm{gpm}$. Feed to the cells comes from classifying cyclone overflow. The only on-line instrumentation currently in place is a dart valve in the tailings box for control of pulp level. An automatic sampling system on the feed, clean coal, and tailings streams provides a consistent set of samples for periodic analysis at the on-site laboratory facility. 


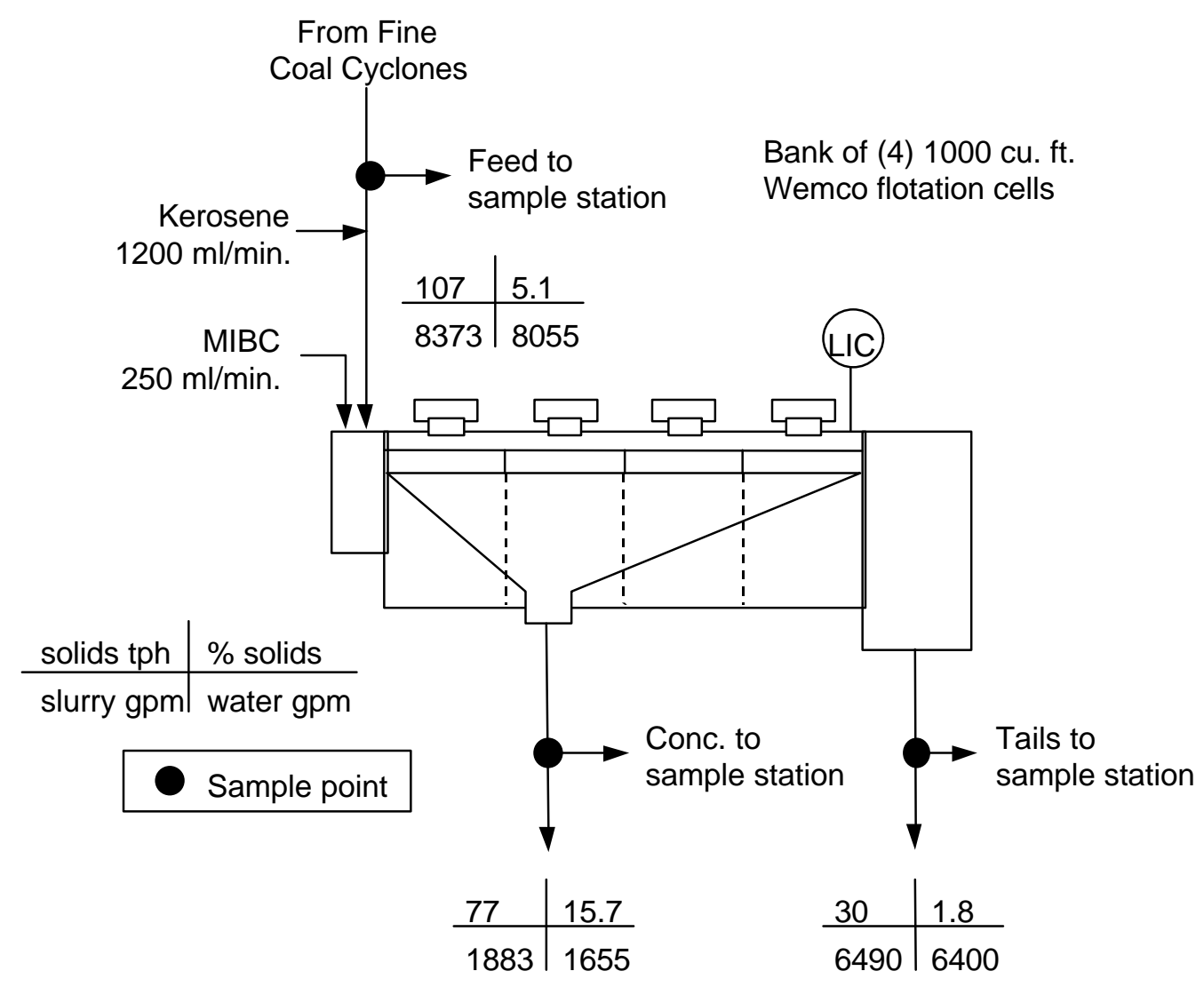

\section{Figure 1. Schematic diagram of Pittston's Moss No. 3 flotation circuit (test F3 values shown).}

The sampling campaign consisted of three types of tests including:

1. a $2^{3}$ factorial design test to determine the effects of collector, frother, and pulp level on the performance of the flotation bank, and to estimate the parameters of a flotation model (The design was blocked into two, half-factorial designs, one at low feed rate and the other at high feed rate.),

2. a residence time distribution test using a lithium chloride tracer, and

3. a series of batch flotation tests using flotation feed samples to determine variability in the floatability of the coal.

A schematic of the $2^{3}$ factorial design is shown in Table 1 . As shown, each variable in the test takes on two values, -1 and +1 , representing high and low levels. This results in four possible combinations plus a center point for each feed rate, producing a 
total of ten tests. The sequence of tests was randomized within each feed rate block. To compare the response of the dynamic flotation model and the plant, transient samples were collected for each test between the time the change in variables was made and the final steady-state was reached. As shown in Figure 2, the change in manipulated variables was made at time $\mathrm{t}=0$, and three transient samples were collected at 3,6 , and 12 minutes. The last sample at 20 minutes was considered to be the steady-state sample. The samples were analyzed for percent ash, percent solids, particle size distribution, and particle composition.

Table 1. Factorial Design Test Summary

\begin{tabular}{ccccc}
\hline Test & Frother & Level & Collector & Feed Rate \\
\hline F1 & -1 & 1 & -1 & +1 \\
F2 & 1 & 1 & 1 & +1 \\
F3 & 0 & 0 & 0 & +1 \\
F4 & -1 & -1 & 1 & +1 \\
F5 & 1 & 1 & -1 & +1 \\
F6 & 1 & 1 & 1 & -1 \\
F7 & -1 & -1 & 1 & -1 \\
F8 & 0 & 0 & 0 & -1 \\
F9 & 1 & 1 & -1 & -1 \\
F10 & -1 & 1 & -1 & -1 \\
\hline
\end{tabular}

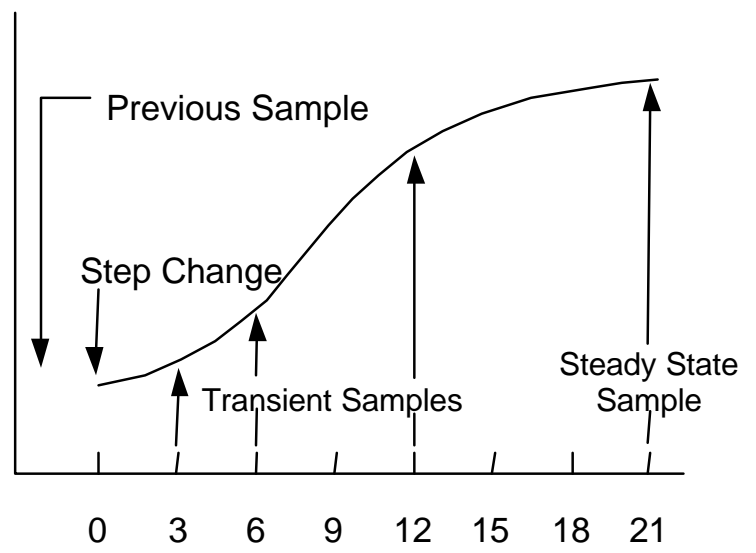

Figure 2. Transient and steady-state samples collected during each test. 
The residence time distribution test was performed using a lithium chloride $(\mathrm{LiCl})$ tracer. One kilogram of $\mathrm{LiCl}$ was dissolved in 4 liters of water and injected into the flotation feed as a pulse at time 0. A series of samples were then collected from the tailings box at 30-second intervals using $500 \mathrm{ml}$ sample bottles. The liquid in the sample bottles was then decanted and analyzed for lithium concentration using atomic absorption.

Variations in coal floatability were characterized using batch flotation tests conducted on feed samples collected at progressively longer intervals between sample times. Initially samples were collected frequently to catch rapid variations. The sample times were then increased in a geometric progression to catch less frequent variations. This technique is less precise than collecting samples for short, equally spaced times, but it greatly reduces the number of samples, and it can catch both short- and long-term disturbances.

As each sample was collected, it was immediately brought to the batch flotation cell so that the chemistry of the batch flotation matched that of the actual plant as closely as possible. The sample was floated in the batch cell for 2 minutes, and all froth was collected during that time. The froth and tails were then filtered and analyzed for ash content.

Subtask 2.2 - Data Analysis: As the first step in Subtask 2.2, all of the assays collected under Subtask 2.1 were mass balanced to provide consistent estimates of mass flowrates, size, composition, and ash content. A description of this mass balance procedure is provided here. 
Mass Balance: The variables used to close the mass balance are shown in Figure

3. The mass balance equations required for this procedure include:

Pulp Mass Flowrate:

$$
M_{F}=M_{C}+M_{T}
$$

Solids Mass Flowrate:

$$
M_{F} p_{F}=M_{C} p_{C}+M_{T} p_{T}
$$

Global Ash Content Flowrate:

$$
M_{F} p_{F} A_{F}=M_{C} p_{C} A_{C}+M_{T} p_{T} A_{T}
$$

Size Mass Flowrate:

$$
M_{F} p_{F} f_{F, l}=M_{C} p_{C} f_{C, l}+M_{T} p_{T} f_{T, l}
$$

Ash Content per Size Flowrate:

$$
M_{F} p_{F} f_{F, l} A_{F, l}^{d}=M_{C} p_{C} f_{C, l} A_{C, l}^{d}+M_{T} p_{T} f_{T, l} A_{T, l}^{d}
$$

Particle Composition per Size Flowrate:

$$
M_{F} p_{F} f_{F, l} f_{F, k}^{d}=M_{C} p_{C} f_{C, l} f_{C, k}^{d}+M_{T} p_{T} f_{T, l} f_{T, k}^{d}
$$

Feed

$$
\begin{array}{ll}
M_{F} & f_{F, l} \\
p_{F} & A_{F, l}^{d} \\
A_{F} & f_{F, k}^{d}
\end{array}
$$

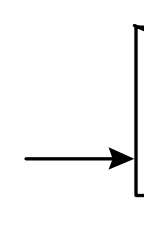

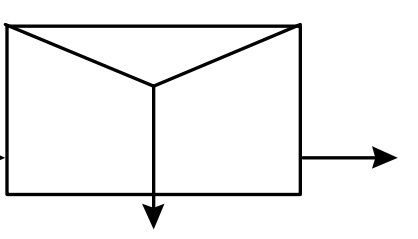

Concentrate

$M_{C} \quad$ Pulp mass flowrate

$p_{C} \quad$ Percent solids

$A_{C} \quad$ Ash content

$f_{C, l} \quad$ Size fraction of size $l$

$A_{C, l}^{d} \quad$ Ash content of size $l$

$f_{C, k}^{d} \quad$ Particle composition class $k$ per size $l$

$p_{T} \quad A_{T, l}^{d}$
Tails

$M_{T} \quad f_{T, l}$

$A_{T} \quad f_{T, k}^{d}$

Figure 3. Flotation cell showing the variables used for the mass balance. 
The adjustment procedure minimizes an objective function based on the least squares criterion (note: $\mathbf{T}$ refers to matrix tranpose):

$$
\underset{w r t}{\operatorname{minimize}}, \hat{\mathbf{z}} \phi=\frac{1}{2}\left(\mathbf{x}_{E}-\hat{\mathbf{x}}\right) \mathbf{W}\left(\mathbf{x}_{E}-\hat{\mathbf{x}}\right)^{\mathrm{T}}
$$

subject to the mass balance constraints (Equations 1-6) of the form

$$
\mathbf{H}(\hat{\mathbf{x}}, \hat{\mathbf{z}})=\mathbf{0}
$$

where $\mathbf{x}_{E}$ are the measured values, $\hat{\mathbf{x}}$ the adjusted values, $\hat{\mathbf{z}}$ the unmeasured flowrates and $\mathbf{W}$ is a weighting matrix whose values are selected by the user to indicate the relative degree of confidence in each measured value. A technique to minimize $\phi$ involves the use of Lagrangian multipliers to incorporate the mass balance constraints, i.e.:

$$
\underset{w r t}{\operatorname{minimize}}, \hat{\mathbf{z}} \phi=\frac{1}{2}\left(\mathbf{x}_{E}-\hat{\mathbf{x}}\right) W\left(\mathbf{x}_{E}-\hat{\mathbf{x}}\right)^{\mathrm{T}}+\boldsymbol{\lambda} \mathbf{H}(\hat{\mathbf{x}}, \hat{\mathbf{z}})
$$

where $\lambda$ are the Lagrangian multipliers.

The solution of Equation (9) is nonlinear if $\hat{\mathbf{z}}$ is unknown and linear if $\hat{\mathbf{z}}$ is known. For unknown $\hat{\mathbf{z}}$ the objective function in Equation (9) is decomposed into sublevels each with a linear solution and then a direct search for the value of $\hat{\mathbf{z}}$ that minimizes $\phi$ is performed. The following is a sample output from the material balance program. The Relative Standard Deviations shown in this output have been selected by the user and are directly related to the weighting matrix, $\mathbf{W}$. 


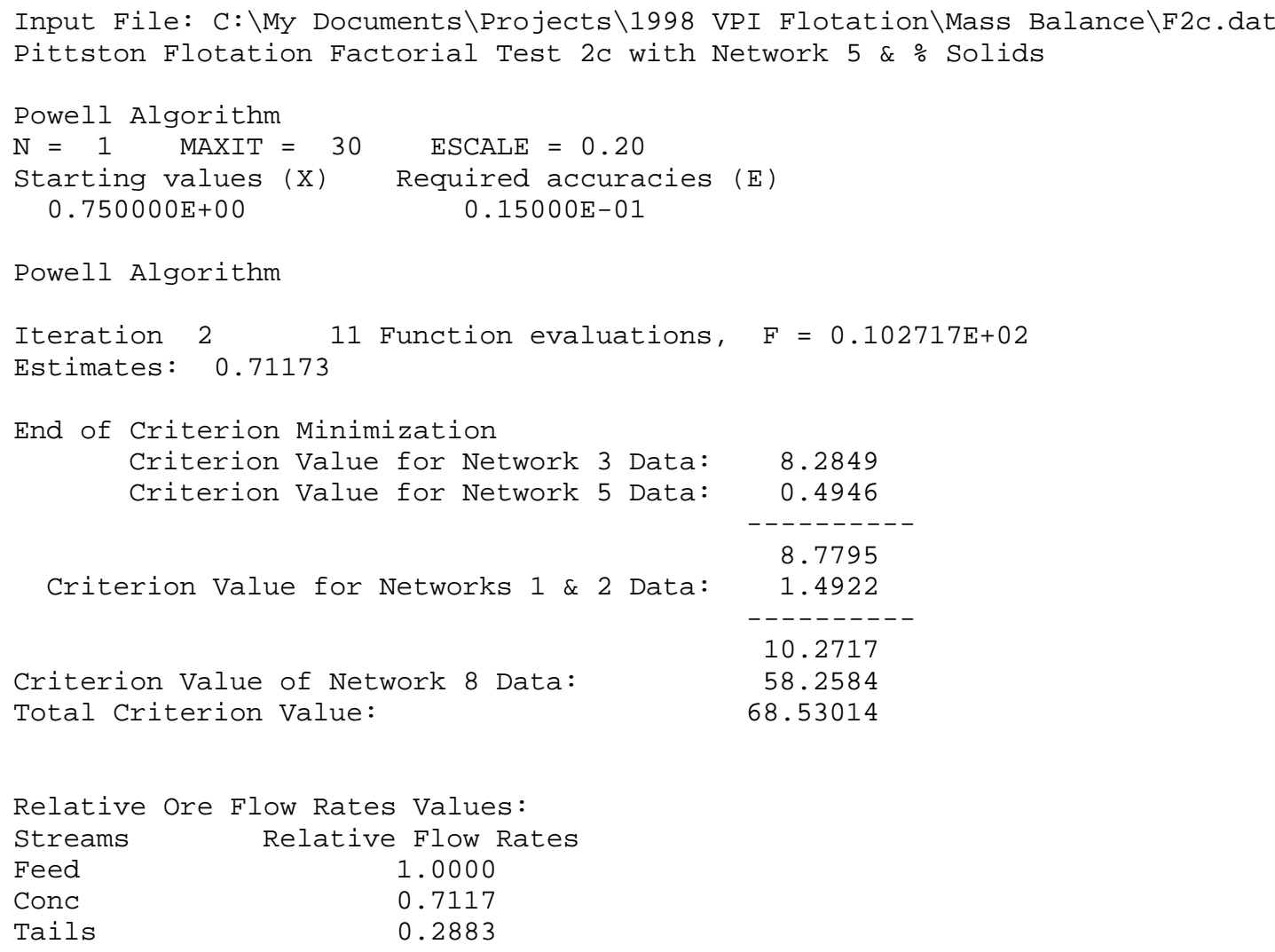




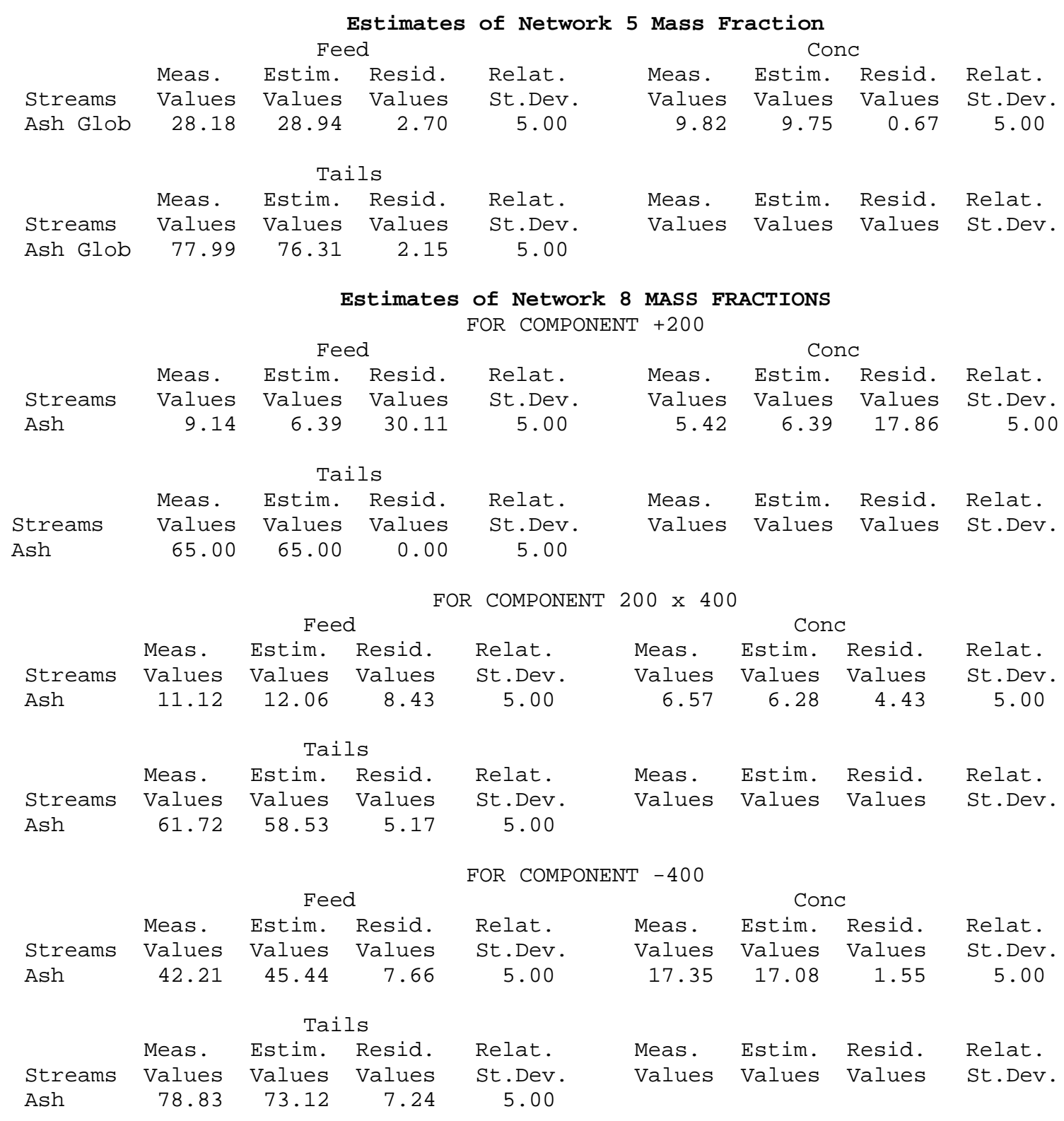

Transient Behavior: Most of the results obtained from the factorial test program were discussed in the Seventh Quarterly Technical Progress Report. Only those results related to the transient behavior study are presented here.

Figure 4 shows the response of percent ash in the concentrate to changes in the manipulated variables at the beginning of each test (refer to Figure 2). In Figure 4 changes are made at time 0 minutes, 20 minutes, and so on. The sample taken 20 minutes 
after a change was made is the sample used for estimation of model parameters in model building. In order for a dynamic model of this process to be accurate, the response of the dynamic simulator to changes in manipulated variables must be similar to that shown in Figure 4. For almost every test an inverse response is seen immediately after a change is made. Thus, these results should provide a good test for the dynamic simulator.

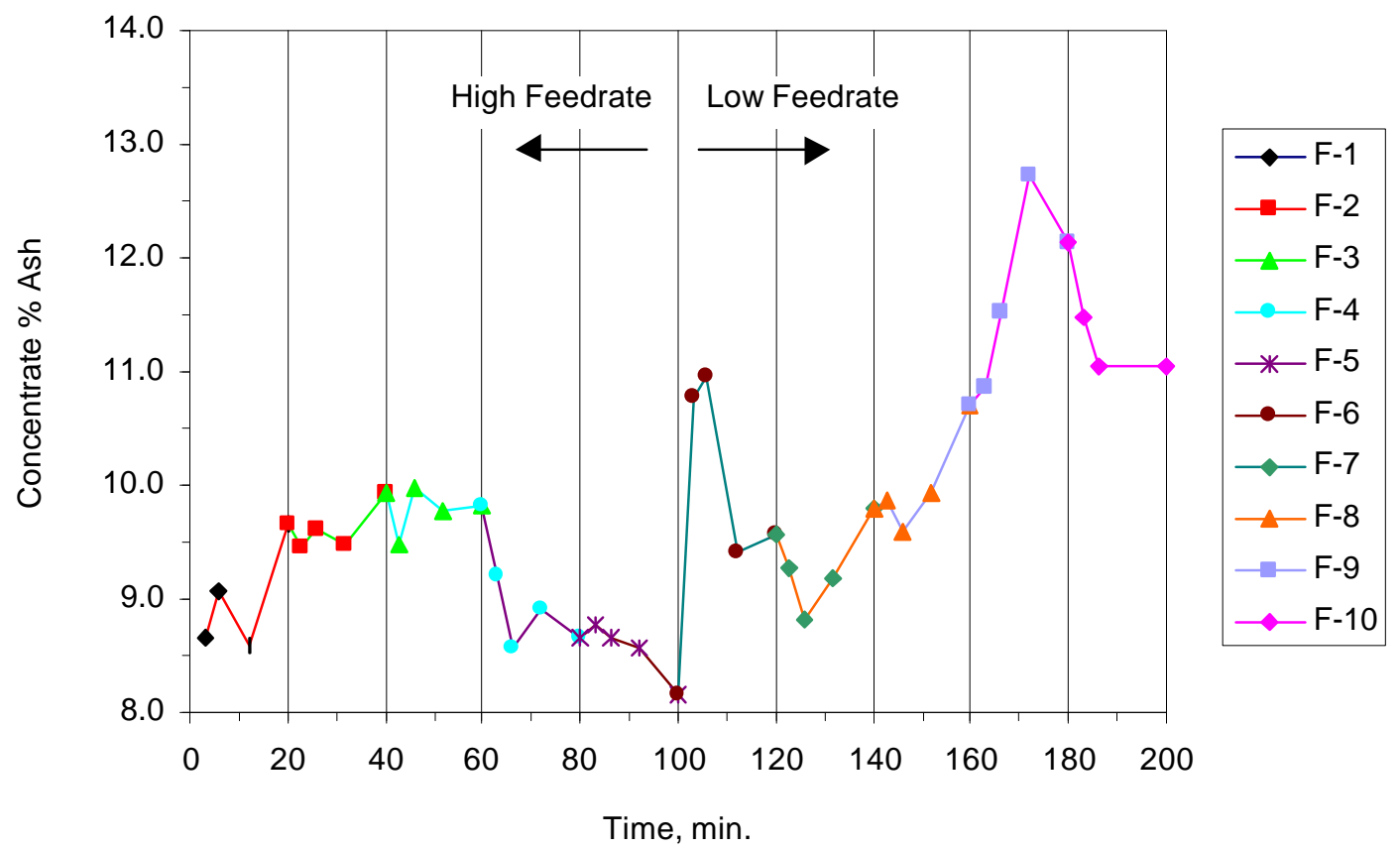

Figure 4. Transient response of $\%$ ash to manipulated variable changes.

\section{Task 3 - Model Building and Computer Simulation}

Subtask 3.1 - Model Building: The purpose of this task is to use the data from Task 2 to produce a dynamic model of the flotation circuit for testing control strategies and implementing a model-based control scheme.

Model Format: The model being used in this investigation is shown schematically in Figure 5. In this figure, particles of size $i$ and composition (i.e., ash content) $j$ exist in four possible states: 1) free in the pulp, 2) attached to bubbles in the 
pulp, 3) free in the froth, and 4) attached to bubbles in the froth. The number of particles of size $i$ and composition $j$ per unit volume in any of the four states is denoted by $\psi_{i j}$. The interphase transfer rate constants, $k$, are also shown.

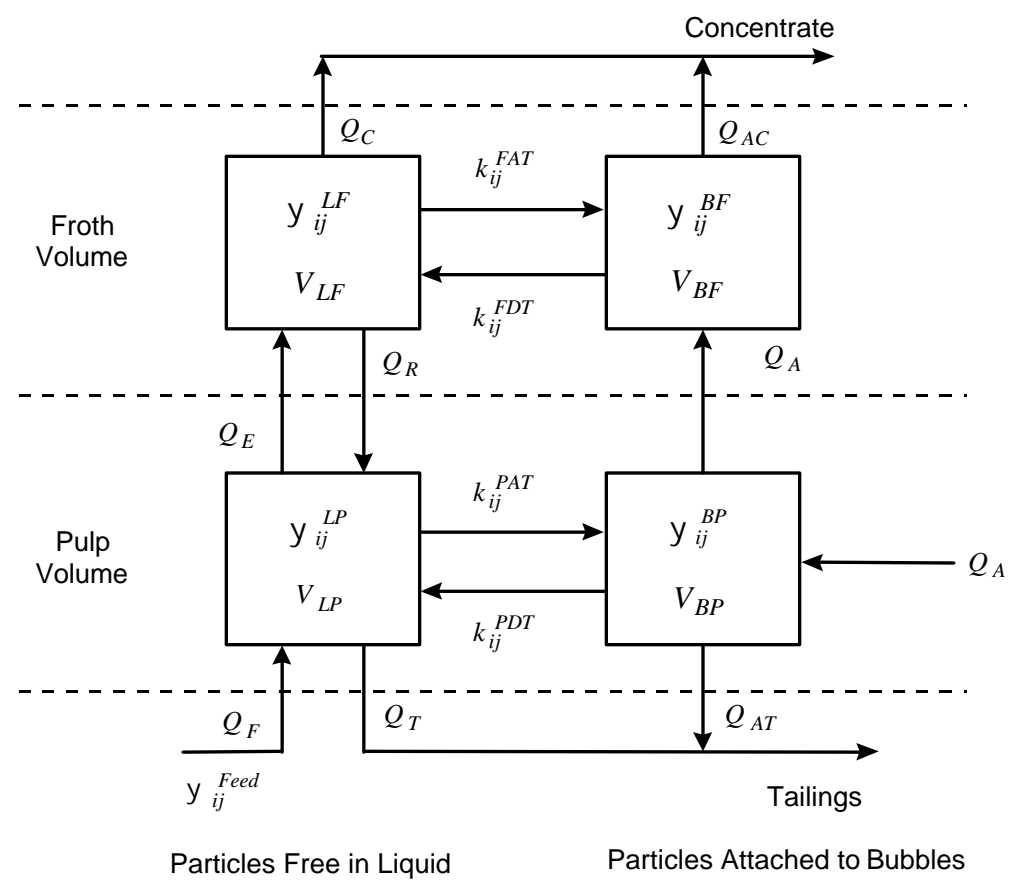

Figure 5. Schematic of the four possible states of particles in a flotation cell.

The population balance framework is an excellent approach for modeling particulate systems that cannot be solved using the usual continuity and rate expressions. A number balance is developed from the general conservation equation:

$$
\text { accumulation }=\text { input }- \text { output }+ \text { generation }
$$

and is applied to particles having a specific set of properties $\left\{\zeta_{1}, \zeta_{2}, \ldots, \zeta_{J}\right\}$. In this balance, input and output terms represent changes in the number of particles in the specified property interval resulting from convective flow, while the generation term accounts for particles entering 
and leaving the specified property interval as a result of individual kinetics. The macroscopic form of the population balance model is applicable when the vessel is well mixed or when residence time distribution information is available. The overall number balances in each of the four states are:

Free in the pulp:

$$
\frac{d}{d t}\left(V_{L P} \psi_{i j}^{L P}\right)+k_{i j}^{P A T} V_{L P} \psi_{i j}^{L P}-k_{i j}^{P D T} V_{B P} \psi_{i j}^{B P}=Q_{F} \psi_{i j}^{F e e d}-Q_{T} \psi_{i j}^{L P}+Q_{R} k_{i j}^{R} \psi_{i j}^{L F}-Q_{E} \psi_{i j}^{L P}
$$

Attached in the pulp:

$$
\frac{d}{d t}\left(V_{B P} \psi_{i j}^{B P}\right)+k_{i j}^{P D T} V_{B P} \psi_{i j}^{B P}-k_{i j}^{P A T} V_{L P} \psi_{i j}^{L P}=-Q_{A} \psi_{i j}^{B P}-Q_{A T} \psi_{i j}^{B P}
$$

Free in the froth:

$$
\frac{d}{d t}\left(V_{L F} \psi_{i j}^{L F}\right)+k_{i j}^{F A T} V_{L F} \psi_{i j}^{L F}-k_{i j}^{F D T} V_{B F} \psi_{i j}^{B F}=Q_{E} \psi_{i j}^{L P}-Q_{C} \psi_{i j}^{L F}-Q_{R} k_{i j}^{R} \psi_{i j}^{L F}
$$

Attached in the froth:

$$
\frac{d}{d t}\left(V_{B F} \psi_{i j}^{B F}\right)+k_{i j}^{F D T} V_{B F} \psi_{i j}^{B F}-k_{i j}^{F A T} V_{L F} \psi_{i j}^{L F}=Q_{A} \psi_{i j}^{B P}-Q_{A C} \psi_{i j}^{B F}
$$

where $\psi_{i j}^{L P}$ is the number of particles free in the liquid in the pulp per volume of liquid in the pulp, $\psi_{i j}^{B P}$ is the number of particles attached to bubbles in the pulp per unit volume of air in the pulp, $\psi_{i j}^{L F}$ is the number of particles free in the liquid in the froth per unit volume of liquid in the froth, $\psi_{i j}^{B F}$ is the number of particles attached to bubbles in the froth per unit volume of air in the froth, and $\psi_{i j}^{\text {Feed }}$ is the number of particles in the feed per unit volume of liquid in the feed. The interphase transfer rates are dependent on particle properties and the chemical and physical environment of the flotation cell where $k_{i j}^{P A T}$ is the particle attachment rate constant in the pulp, $k_{i j}^{P D T}$ is the particle detachment 
rate constant in the pulp, $k_{i j}^{F A T}$ is the particle attachment rate constant in the froth and $k_{i j}^{F D T}$ is the particle detachment rate constant in the froth. The input flows are: 1) the feed of particles into the flotation cell, $Q_{F} \psi_{i j}^{\text {Feed }}$, where $Q_{F}$ is the liquid volume flowrate, and 2) the return flow rate of particles draining from the froth carried by the water, $Q_{R} k_{i j}^{R} \psi_{i j}^{L F}$, where $Q_{R}$ is the volumetric flowrate of water draining from the froth and $k_{i j}^{R}$ is a dimensionless classification constant representing the segregation that occurs in the draining liquid in the froth. The output flows are: 1) the flowrate of particles leaving through the tailings port, $Q_{T} \psi_{i j}^{L P}$, where $Q_{T}$ is volumetric flowrate of liquid in the tails, and 2) the flowrate of particles entrained by the water flow, $Q_{E} \psi_{i j}{ }^{L P}$, where $Q_{E}$ is the volumetric flowrate of water to the froth transported in the bubble film and wake.

Model Simplification: When adapting this detailed model for use in model-based control, the online model must be simple for quickness and robustness; however, the simplified model must not be so simple that it fails to approximate the first order behavior of the process. The assumptions that lead to an accurate yet simple model are:

1) Coal is a highly hydrophobic material so that the rates of attachment in both pulp and froth phases are much larger than detachment, i.e., $k_{i j}^{P A T}>>k_{i j}^{P D T}$ and $k_{i j}^{F A T} \gg>k_{i j}^{F D T}$. This is not a good assumption for hydrophilic or weakly hydrophobic ash particles, and it introduces a certain amount of error into the predictive capabilities of the model since attachment and detachments rates are affected by the manipulated variables differently. However, since entrainment of ash particles is more significant than flotation of ash particles the error is not serious. 
2) Drainage of water from froth to pulp is much less than entrained water from pulp to froth, i.e. $Q_{E} \gg Q_{R}$. Drainage is more important in flotation cells that have wash water added to the froth, such as flotation columns.

3) The small amount of middlings material present in this coal (see Figure 6) means that the sample can be represented by two composition classes; a class containing $100 \%$ carbonaceous material to be referred to as "clean coal" and a class containing $100 \%$ mineral matter to be referred to as "ash".

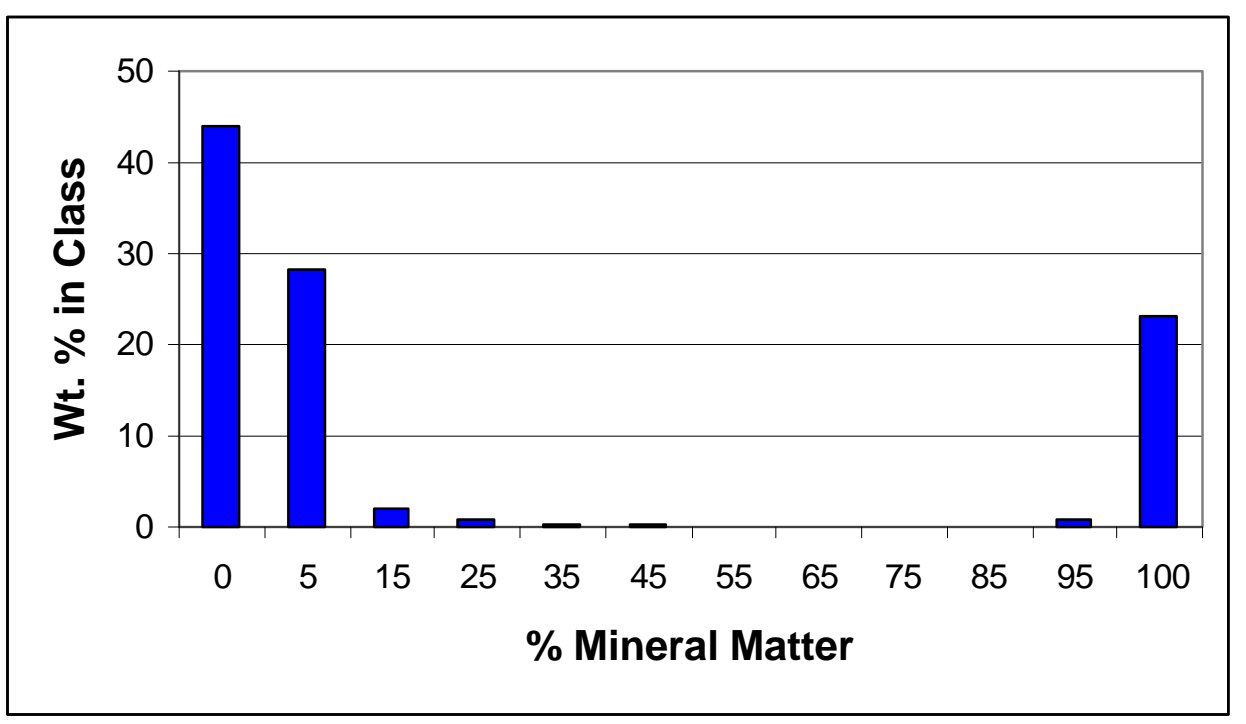

Figure 6. Particle composition distribution for the feed sample from factorial test 2.

Entrainment: The rate at which a particle class is entrained into the froth is, to a good approximation, proportional to its concentration in the pulp liquid phase. The mass flowrate of a particle class into the froth by entrainment for the $k$ th cell, $\dot{M}_{E, i j k}$, is given by:

$\dot{M}_{E, i j k}=Q_{E, k} \psi_{i j k}^{L P}$ 
Experimentally, entrainment can be calculated by determining the recovery of water from the flotation bank. If it is assumed that the entrained water has the same composition of solids as the pulp in the bank (a valid assumption for a well-mixed system), the clean coal and ash recovered by entrainment can be separated from the clean coal and ash recovered by attachment to bubbles.

Figures 7 and 8 show how much of the clean coal is recovered in the froth product by entrainment and by flotation. The amount recovered by entrainment is small because so much of the clean coal is floated that the concentration of clean coal in the pulp is low.

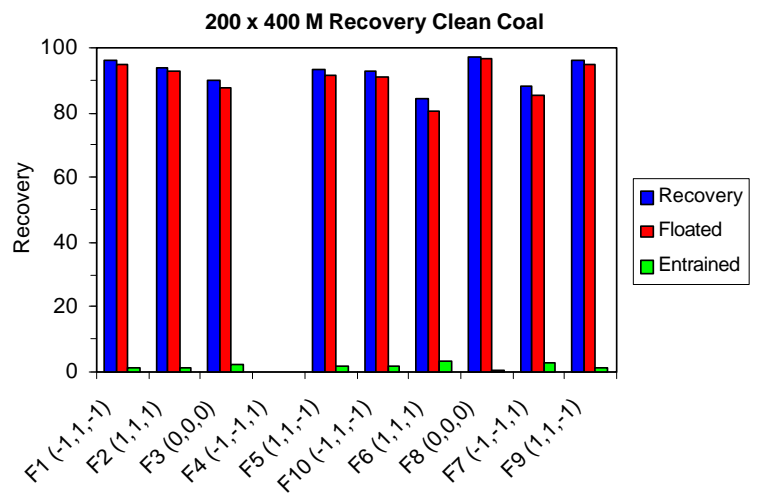

Figure 7. Clean Coal $200 \times 400$ Mesh.

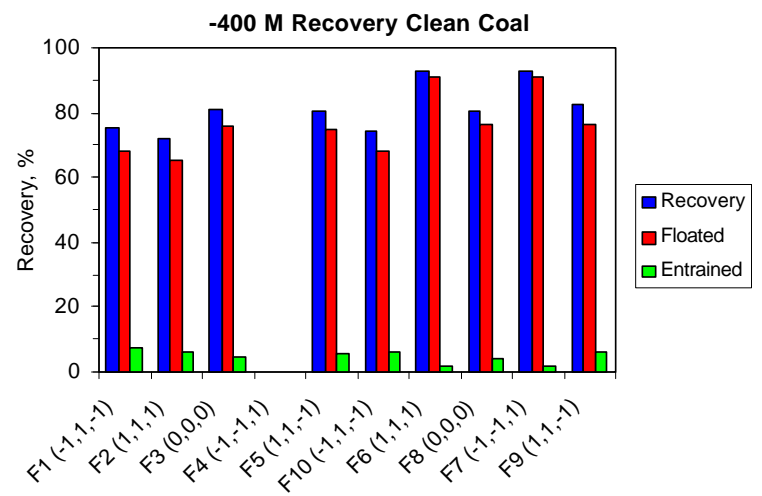

Figure 8. Clean Coal -400 Mesh.

Figures 9 and 10 show how much of the ash is recovered in the froth product by entrainment and by flotation. The relative amount of ash recovered into the froth by entrainment is larger than it is for clean coal because the concentration of ash is higher in the pulp. 


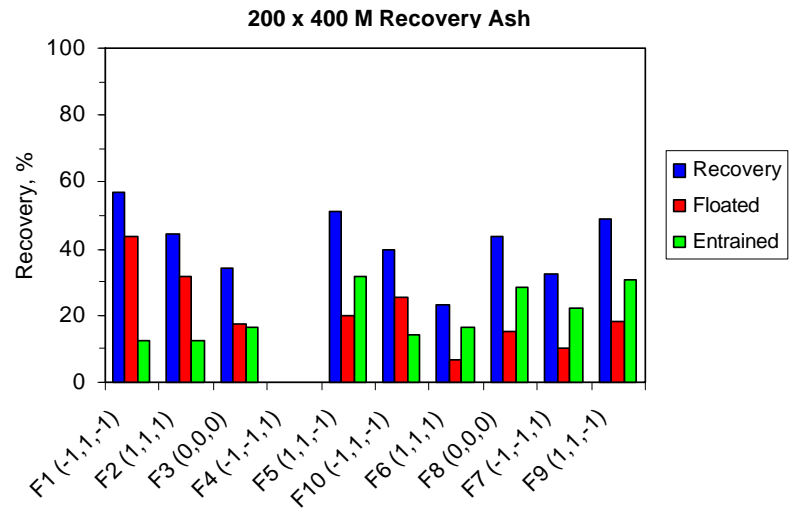

Figure 9. Ash $200 \times 400$ Mesh.

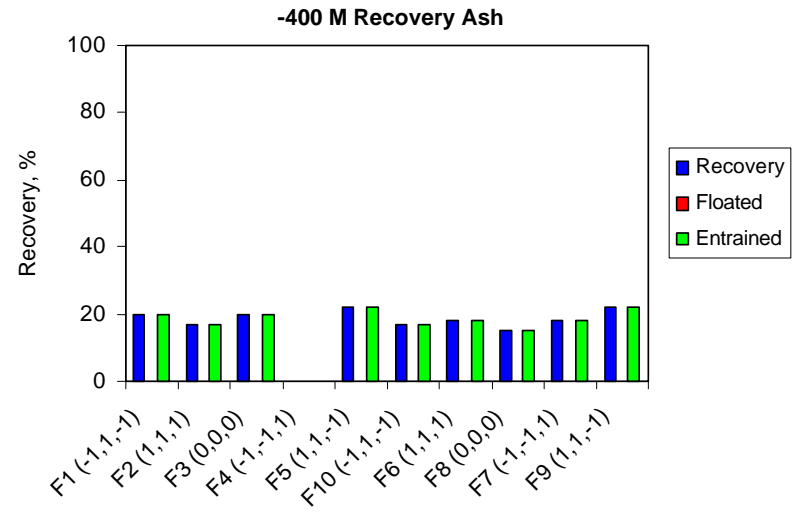

Figure 10. Ash -400 Mesh.

Flotation Rate Parameter Estimates: The simplified model has only a single flotation rate parameter for each particle class, $k_{i j}$. At steady-state the simplified model can be solved for each $k_{i j}$ if the retention time is known. If the retention time is not known then $k_{i j} \tau$ (a quantity proportional to the overall probability flotation) can be calculated. Since the residence time distribution (RTD) test was performed only at the high feed rate, then only $k_{i j} \tau$ was calculated for each test. Figures 11 and 12 show $k_{i j} \tau$ versus particle size for the clean coal particles at high and low feed rates, respectively. Since all +200 Mesh material was found to be low ash (i.e., < 7\%), no +200 Mesh particles reported to the tail. Thus, the rate parameter for the +200 Mesh size interval is, mathematically, infinite. For practical purposes a high rate, $k_{+200 \mathrm{M}, j}=3$, was assumed as shown in the plots. At low feed rate (i.e., higher retention time) the center point resulted in the highest flotation probability $\left(k_{i j} \tau\right)$ while at high feed rate (i.e., lower retention time) the center point resulted in the lowest probability. At high feed rate there appears to be some opportunity for increasing recovery of the 200 x 400 Mesh clean coal class. However, with the exception of two conditions at low feed rate, the flotation 
probability of the -400 Mesh material is insensitive to the manipulated variables. Thus, there appears to be little opportunity for increasing recovery of the -400 Mesh material through the use of a control system. Similarly there appears to be no opportunity for increasing recovery of the +200 Mesh material since it is essentially all floated.

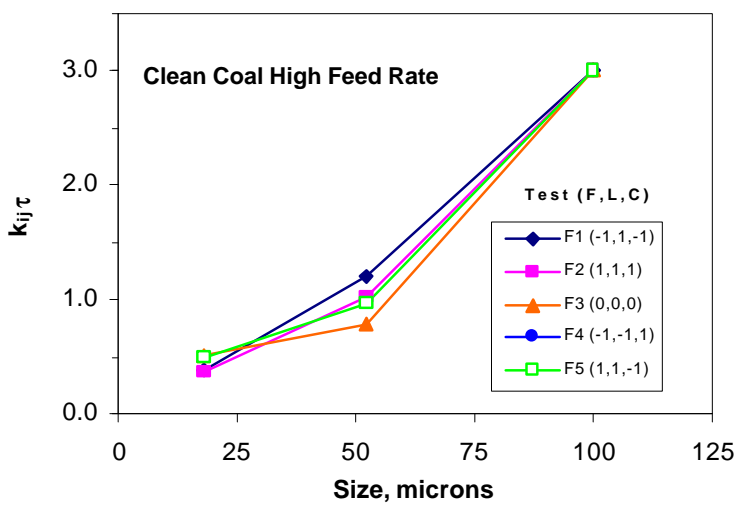

Figure 11. Clean coal high feed rate.

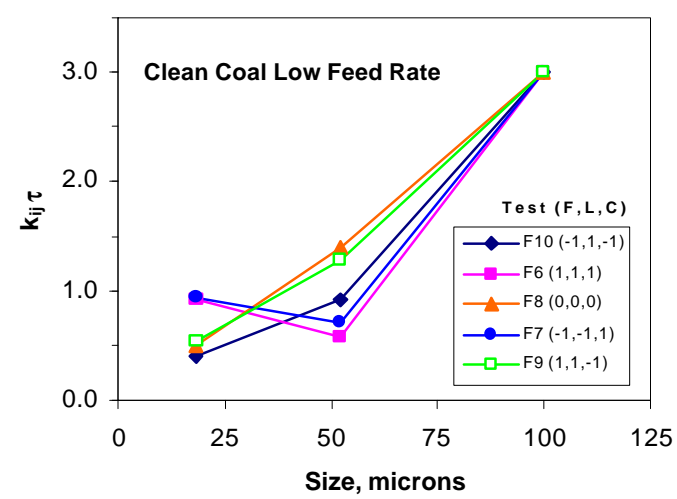

Figure 12. Clean coal low feed rate.

Increasing the feed rate (i.e. decreasing residence time) reduced the flotation probability at the center point, but the behavior at other conditions when the feed rate was increased is more complicated.

Figure 13 shows that increasing all three manipulated variables at low feed rate increases the flotation probability of the $200 \times 400$ Mesh material, but Figure 14 shows the opposite effect at high feed rate. The explanation may have to do with the high loading of bubbles, but it is unclear at this time what is actually going on. Figure 14 also shows that increasing the residence time did not increase the $k_{i j} \tau$ parameter for all sizes, which is somewhat puzzling, but again it may have something to due with bubble loading. 


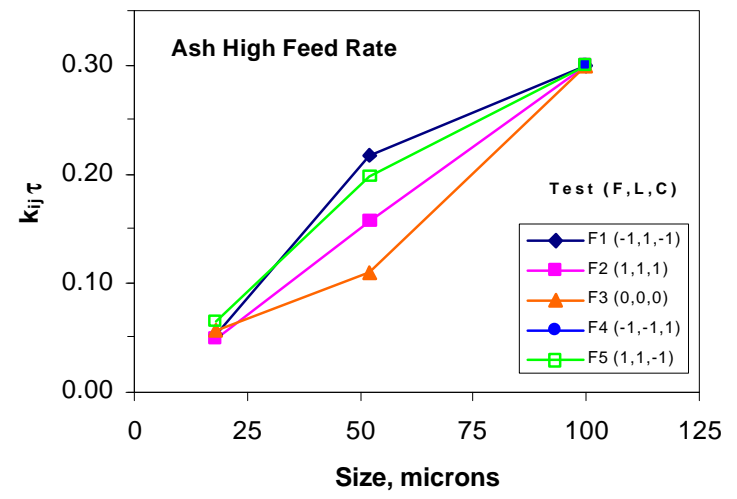

Figure 13. Ash at high feed rate.

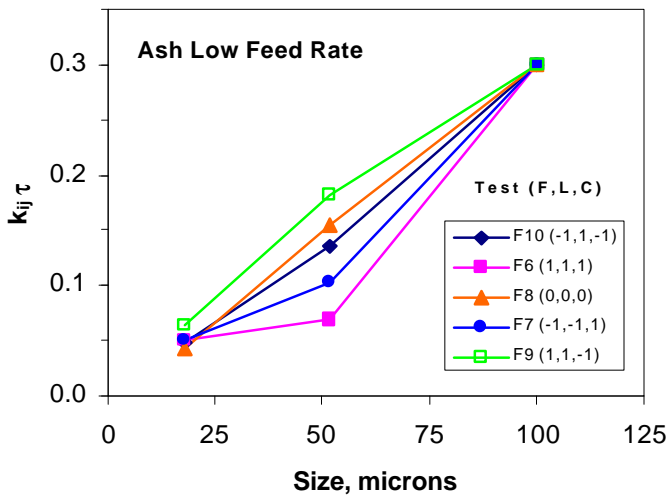

Figure 14. Ash at low feed rate.

Residence Time Distribution: The impulse response of an N-mixers-in-series vessel is given by:

$\frac{C(t)}{C(0)}=\tau E(t)=\frac{N^{N}(t / \tau)^{N-1}}{\Gamma(N)} e^{-N(t / \tau)}$

where $C(t)$ is the concentration at the exit of the vessel, $C(0)$ is the concentration in the vessel at time $0, N$ is the number of mixers and $\tau$ is the residence time of the vessel. (The mean residence time is $\tau=V / Q$.)

Figure 15 shows the $\mathrm{Li}$ concentration response from the $2 \mathrm{~kg}$ impulse. The parameters that produce the best fit when $N=4$ (the number of flotation cells) are $\tau=4.0$ minutes and $C(0)=5.0 \mathrm{mg} / \mathrm{l}$. The flowrate of slurry calculated from $Q=V / \tau$ is $Q=4000$ $\mathrm{ft}^{3} / 4 \mathrm{~min}=1000 \mathrm{ft}^{3} / \mathrm{min}=7480 \mathrm{gpm}$. The fit is not exact because there appears to be about 45 seconds of dead time and the experimental tail goes to the background level slowly. However the fit is close enough that approximating the residence time with 4 perfect mixers in series should not introduce much error. 


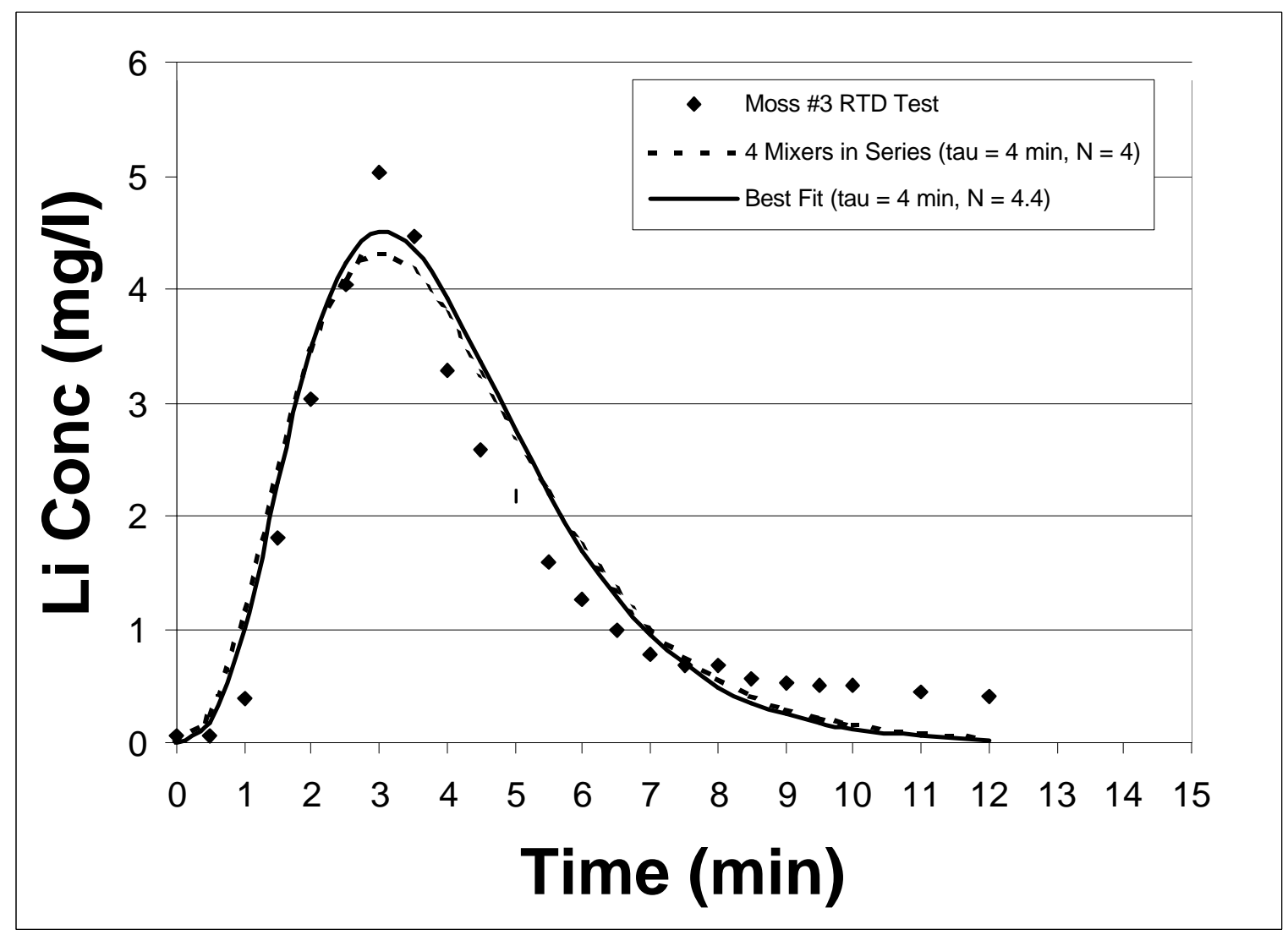

Figure 15. The experimental and fitted residence time distributions.

The value of $7480 \mathrm{gpm}$ for the low feed rate condition, combined with values of $k_{i j} \tau$ for both low and high feed rates, allow the estimation of flow for the high feed rate tests. The estimated value is $8378 \mathrm{gpm}$. This change is reasonably close to the 10 percent change in feed rate made in the plant.

Floatability Disturbances: Feed samples were collected at geometrically increasing times and taken immediately to the laboratory for batch flotation tests. The concentrate and tails were analyzed for weight and percent ash to calculate a simple first order flotation rate constant for each feed sample, see Figure 16. The sample at time 0 cannot be plotted on a log scale so for convenience it is plotted at time $=1$ minute. Two 
large changes in flotability take place at 4 and 12 minutes. The magnitute of the changes, about 60 percent, are large and will provide a stiff test for the control system.

The relationship between the rate parameters and the reagents will be determined next quarter. A linear regression model will be used because a microscopic/fundamental model has never been developed for the relationship between the phenomenological rate parameters and the physical/chemical environment in the flotation cell.

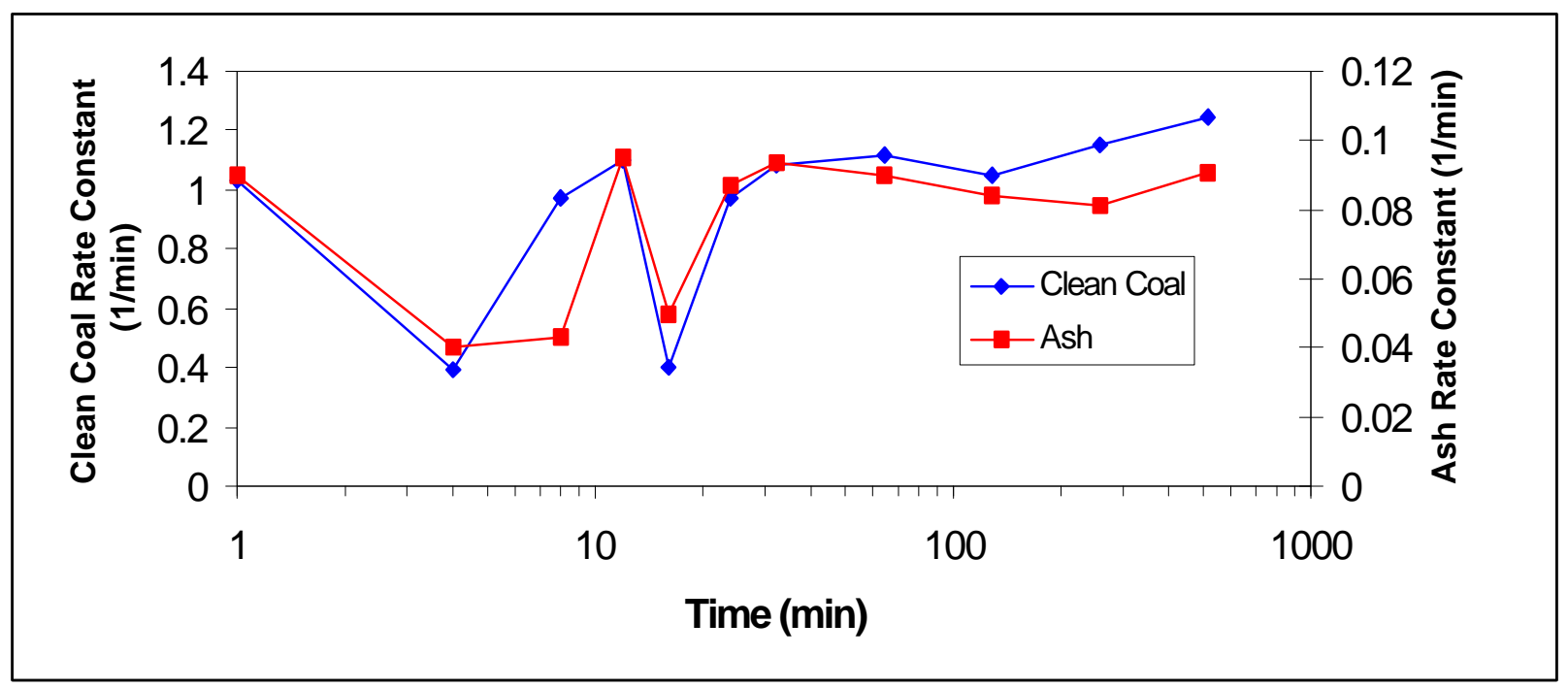

Figure 16. Floatability disturbances.

Subtask 3.2 - Simulator Development: The change to the Pittston test site has slowed simulator development somewhat. The $\mathrm{C}++$ code for a flotation cell object has been written and will be tested in a dynamic simulator. A generic Kalman filter object is available to be used in conjunction with the flotation cell object to form the estimator. The optimizer object will be written in C++. It is expected that this subtask will be completed early in the next quarter.

Subtask 3.3 - Control Strategy Evaluation: The greatest strength of model-based control strategies is that they allow powerful decision making based on quantitative on- 
line estimates of floatability changes in the plant and accurate predictions of the impact of changes in manipulated variables. The Moss No. 3 plant objective is to maximize incremental ash without exceeding $38 \%$. This figure was arrived at through consultation with Pittston personnel, and is financially driven. The control system that is being developed as part of this project will use the flotation model to maintain incremental product ash as close to $38 \%$ as possible. This will be done by maximizing the quantity:

$\left[\frac{d(\% \text { Ash })}{d(\% \text { Yield })}\right]_{\text {Last Cell }}=f($ Frother, Collector, Level $)$

with respect to the manipulated variables of frother, collector, and level on a moment-tomoment basis. Additional control strategies may be tested, but this is the most desirable strategy from Pittston's point-of-view.

Subtask 3.4 - Expert System Development: Work on this subtask has just begun with completion planned for May, 1998.

\section{Task 4 - Sensor Testing}

Subtask 4.1 - Calibration Testing: After several months of delay waiting for Pittston personnel to install a non-plugging sample line, the existing video-based ash analyzer is now undergoing extensive testing at Pittston's Middle Fork preparation plant. The purpose of these tests is to provide information on long-term durability and reliability of the sensor under rigorous plant conditions. Specifications have been prepared for a system to be installed at the Moss No. 3 plant and installation of a sample line at this site is now underway. It is expected that all calibration and testing of the video-based ash analyzer will be completed by June 1, 1998 . 
Subtask 4.2 - Design and Fabrication: This subtask is essentially complete barring any changes suggested by continued testing at the Middle Fork and Moss No. 3 sites.

\section{Task 5 - Sample Analysis and Characterization}

Sample analysis is continuing as samples are collected under Task 4. All sample analysis and characterization work is on schedule.

\section{Task 6 - Equipment Procurement and Installation}

Following the testing of design modifications related to the video-based ash analyzer, specifications for the system to be installed as part of the Moss No. 3 control system have now been established. All other equipment specifications are nearly complete, and should be finalized by April or early May, 1998, based on control strategy simulations.

\section{Task 7 - Operation and Testing}

Due to delays in completing Task 3, this task will likely be delayed until July, 1998.

\section{$\underline{\text { Task } 8 \text { - System Evaluation }}$}

Due to delays in completing Task 3, this task will likely be delayed until August, 1998.

\section{Task 9 - Decommissioning}

This task is scheduled to begin in January, 1999.

\section{$\underline{\text { Task } 10 \text { - Final Report }}$}

This task is scheduled to begin in February, 1999. 


\section{SUMMARY STATUS AND FUTURE WORK}

Major accomplishments during the past quarter were the completion of all data analysis

under Task 2 - Sampling and Data Analysis and the development of a mathematical model of the flotation process as part of Task 3 - Model Building and Computer Simulation. As a result of this work, the following conclusions can be drawn:

1. The assays collected from the sampling campaign appear to be reasonable based on the minimal adjustments required for material balancing.

2. Dynamic analysis of the transient response obtained after an operating parameter is changed indicates that there is an initial inverse response in clean coal ash content before a new steady-state is reached. This inverse response should provide a good test for validating the dynamic simulation model.

3. A model structure has now been identified and several simplifying assumptions have been incorporated to make the model useful for on-line purposes.

4. A size and composition analysis of the plant flotation data indicates that nearly all clean coal recovery is due to particle attachment to air bubbles. Entrainment only appears to be significant for -400 mesh ash particles.

5. An analysis of the flotation rate constants determined from plant data indicates that there is some opportunity for a control system to improve the flotation of the $200 \times 400$ mesh clean coal, while changes in operating parameters seem to have little effect on the +200 and -400 mesh material.

6. Residence time distribution tests indicate that the four-cell flotation bank at the Moss No. 3 plant behaves like four mixers in series with a mean retention time of four minutes. This result is especially convenient for mathematical modeling.

7. Disturbances in the system due to changes in flow rate seem to correlate with the overall changes in plant flow rate. However, batch flotation tests seem to indicate that there may be some short-term disturbances arising from uncontrolled changes in chemistry or coal floatability. As mentioned in the previous quarterly report, these short-term disturbances may actually be an anomaly of the testing procedure and should be taken with a grain of salt.

8. Simulator development and control strategy evaluation are now underway. A control strategy of maintaining a 38\% incremental ash off of the last flotation cell has been agreed upon with Pittston personnel as the primary control strategy to be investigated in this project.

9. Following the installation of a non-plugging sample line, sensor testing has now resumed. All sensor calibration and testing is expected to be completed by May, 1998. 
Work is progressing well, and it appears that the delay caused by switching test sites has only set the project back by three months. It is expected that the model building and simulator development work under Task 3 and the sensor testing work under Task 4 will be completed by the end of the next quarter. This should make it possible to begin in-plant testing of the control system by July, 1998. 


\section{NOMENCLATURE}

$A_{C} \quad$ - ash content of the concentrate.

$A_{F} \quad$ - ash content of the feed.

$A_{T} \quad$ - ash content of the tailings.

$A_{C, l}^{d} \quad$ - ash content of size class $l$ material in the concentrate stream.

$A_{F, l}^{d} \quad$ - ash content of size class $l$ material in the feed stream.

$A_{T, l}^{d} \quad$ - ash content of size class $l$ material in the tailings stream.

$\mathrm{C}(\mathrm{t})$ - concentration of tracer in the exit stream of a vessel (mass/volume).

$\mathrm{C}(0)$ - concentration of tracer in a vessel at time $=0$ (mass/volume).

$f_{C, l} \quad$ - mass fraction of size $l$ in the concentrate.

$f_{F, l} \quad$ - mass fraction of size $l$ in the feed.

$f_{T, l} \quad$ - mass fraction of size $l$ in the tailings.

$f_{C, k}^{d} \quad$ - particle composition class $k$ of size class $l$ material in the concentrate stream.

$f_{F, k}^{d} \quad$ - particle composition class $k$ of size class $l$ material in the feed stream.

$f_{T, k}^{d} \quad$ - particle composition class $k$ of size class $l$ material in the tailings stream.

i - size class.

j - composition class.

$k \quad-$ rate constant $\left(\right.$ time $\left.^{-1}\right)$.

$k_{i j}^{F A T}$ - particle attachment rate constant in the froth $\left(\right.$ time $\left.^{-1}\right)$.

$k_{i j}^{F D T}$ - particle detachment rate constant in the froth $\left(\right.$ time $\left.^{-1}\right)$.

$k_{i j}^{P A T}$ - particle attachment rate constant in the pulp (time $\left.{ }^{-1}\right)$.

$k_{i j}^{P D T}$ - particle detachment rate constant in the pulp (time $\left.{ }^{-1}\right)$. 
$k_{i j}^{R} \quad$ - dimensionless classification constant representing the segregation of particles occurring in the draining liquid of the froth.

$M_{C} \quad$ - mass flow rate of pulp in the concentrate stream.

$M_{F} \quad$ - mass flow rate of pulp in the feed stream.

$M_{T} \quad$ - mass flow rate of pulp in the tailings stream.

$\dot{M}_{E, i j k}$ - mass flow rate of particles into the froth by entrainment for the $k$ th cell.

$\mathrm{N} \quad$ - number of perfect mixers in series.

$p_{C} \quad$ - percent solids in the concentrate stream.

$p_{F} \quad$ - percent solids in the feed stream.

$p_{T} \quad$ - percent solids in the tailings stream.

$Q_{A} \quad$ - volumetric flow rate of air into the flotation bank (volume/time).

$Q_{A C} \quad$ - volumetric flow rate of air leaving the top of the froth (volume/time).

$Q_{A T} \quad$ - volumetric flow rate of air leaving with the tailings stream (volume/time).

$Q_{C} \quad$ - volumetric flow rate of liquid leaving with the concentrate (volume/time).

$Q_{E} \quad$ - volumetric flow rate of water transported to the froth due to entrainment in the bubble film and wake (volume/time).

$Q_{F} \quad$ - volumetric flow rate of liquid in the feed stream (volume/time).

$Q_{R} \quad$ - volumetric flow rate of water draining from the froth (volume/time).

$Q_{T} \quad$ - volumetric flow rate of liquid in the tailings stream (volume/time).

t - time.

$V_{B F} \quad$ - volume of air in the froth.

$V_{B P} \quad$ - volume of air in the pulp. 
$V_{L F} \quad$ - volume of liquid in the froth.

$V_{L P} \quad$ - volume of liquid in the pulp.

W - material balance weighting matrix.

$\hat{\mathrm{x}} \quad$ - vector of adjusted assays in a material balance calculation.

$\mathrm{X}_{\mathrm{E}} \quad$ - vector of measured assays in a material balance calculation.

$\hat{\mathrm{Z}} \quad$ - vector of unmeasured flow rates in a material balance calculation.

$\phi \quad$ - material balance objective function.

$\lambda \quad$ - Lagrangian multiplier.

$\tau \quad-$ mean residence time in a vessel.

$\psi_{i j} \quad$ - number concentration of particles of size $\mathrm{i}$ and composition $\mathrm{j}$ (number/volume).

$\psi_{i j}^{B F} \quad$ - number of particles attached to bubbles in the froth per unit volume of air in the froth

$\psi_{i j}^{B P} \quad$ - number of particles attached to bubbles in the pulp per unit volume of air in the pulp

$\psi_{i j}^{\text {Feed }}$ - number of particles in the feed per unit volume of liquid in the feed.

$\psi_{i j}^{L F} \quad$ - number of particles free in the liquid in the froth per unit volume of liquid in the froth.

$\psi_{i j}^{L P} \quad$ - number of particles free in the liquid in the pulp per unit volume of liquid in the pulp. 